\title{
RESULTS OF FINITE ELEMENT ANALYSIS FOR INTERLAMINAR FRACTURE REINFORCED THERMOPLASTIC COMPOSITES
}

\author{
P.J. Charitidis \\ Center of Orthopaedic Research (C.O.RE) at Center for Interdisciplinary Research and \\ Innovation-Aristotle University of Thessaloniki ( CIRI-AUTH), Greece
}

\begin{abstract}
The double cantilever beam (DCB) is widely used for fracture toughness testing and it has become popular for opening-mode (mode I) delamination testing of laminated composites. Delamination is a crack that forms between the adjacent plies of a composite laminate at the brittle polymer resin. This study was conducted to emphasize the need for a better understanding of the DCB specimen of different fabric reinforced systems (carbon fibers) with a thermoplastic matrix (EP, PEI), by using the extended finite element method (X-FEM). It is well known that in fabric reinforced composites fracture mechanisms include microcracking in front of the crack tip, fiber bridging and multiple cracking, and both contribute considerably to the high interlaminar fracture toughness measured. That means, the interlaminar fracture toughness of a composite is not controlled by a single material parameter, but is a result of a complex interaction of resin, fiber and interface properties.
\end{abstract}

\section{KEYWORDS:}

double cantilever beam, FEA, fabric reinforced composites, thermoplastic matrix, X-FEM

\section{INTRODUCTION}

A unidirectional continuous fiber reinforcement in high performance composite materials leads to high specific strength and stiffness in fiber direction but very low properties transverse to it. Usually laminates made of plies with different fiber orientation or of plies with woven fabric fiber reinforcement are used in structures to overcome this problem in three dimensions. A critical failure mode of these laminates is the interlaminar fracture or the delamination [1-4]. Delamination can occur during the manufacturing process due to contaminated reinforcing fibers, insufficient wetting of fibers, machining and mechanical loading such as impact loading. Delamination can also occur due to the lack of reinforcement in the thickness direction and, also, since interlaminar stresses exist in the boundary layer of laminates under transverse loading [5,6,7]. Components made of epoxy-based materials have provided out- standing mechanical, thermal, and electrical properties [8]. The laminated fiber-reinforced composite materials such as carbon fiber epoxy composites are widely applied in packaging, coating, electronics, automotive, and aerospace industries [9,10]. They have high strength-to-weight and stiffness-to-weight ratios. These composites have unique advantages over monolithic materials, such as high strength, high stiffness, long fatigue life, low density, corrosion resistance, wear resistance, and environmental stability [11]. Mechanical properties of epoxy polymeric composites can be enhanced through the improvement of the interlaminar properties by toughening resin matrix [12,13], and fiber reinforcement $[14,15]$. In unidirectional carbon and glass fibre with epoxy matrices, typical values of interlaminar fracture toughness $G_{\text {Ic }}$ are in the range 200-400 J/m 2 . Modification of the epoxy matrix with rubber particles leads to improvement in $\mathrm{G}_{\mathrm{Ic}}$ up to approximately $800-1000 \mathrm{~J} / \mathrm{m}^{2}$. For composites reinforce by woven glass fibres typical values of the fracture toughness are $\approx 1000 \mathrm{~J} / \mathrm{m}^{2}$ 
[16]. A lot of investigations have been published so far dealing with the measurement of the critical energy to cause delamination and to characterize the materials by means of this property. However, most of these studies were carried out using unidirectional reinforced laminate specimens and were focused on the test procedure, geometry and data reduction methods. In order to predict delamination onset or growth for two-dimensional problems, these calculated $G$ components are compared to interlaminar fracture toughness properties measured over a range from pure mode I loading to pure mode II loading [17, 18]. Simulating the propagation of cracks by using finite element method is quite challenging because the topology of the domain changes continuously. For this reason, the extended finite element method (XFEM) is being used to model cracks because the mesh can be created independent from the crack geometry. Actually, XFEM lies in applying the appropriate enrichment function locally in the domain of interest using the partition of unity. This method was first proposed by Belytschko et al. [19], where they applied the partition of unity methods to the problem of using finite elements with discontinuous basis functions. Further on, Moes, et. al. [20], used XFEM to create a technique for simulating crack propagation in two dimensions without remeshing the domain, while the extension to three dimensions was begun by Sukumar et al. [21], where they used the two dimensional enrichment functions for planar cracks, and then extended in [22-26]. XFEM has demonstrated more accurate and stable solutions while the conventional finite element results were rough or highly oscillatory $[27,28]$. In this study we trying to analyzing stress distribution for the local region ahead the crack tip for a very thin resin layer by using extended finite element method (Abaqus). This thickness which is almost $0.0004 \mathrm{~mm}$, was "received" by the experimental procedure [29, 30], which indicates a very thin resin-rich layer between neighboring plies.

\section{ANALYTICAL THEORIES}

\subsection{SIMPLE BEAM THEORY}

The simple beam theory expression for the compliance of a perfectly built-in DCB specimen results in the following equation for $\mathrm{G}_{\mathrm{Ic}}$ :

$$
G_{I c}=\frac{3 P \delta}{2 B \alpha}
$$

where $\mathrm{P}$ and $\delta$ are the load and displacement values, respectively calculated from the P- $\delta$ curve at the point of deviation from linearity, determined by drawing a straight line from the origin but ignoring any initial deviations due to take-up of play in the loading system [31]. Furthermore, $\mathrm{B}$ is the specimen width and $\alpha$ the initial crack length.

\subsection{CORRECTED BEAM THEORY}

The above expression will underestimate the compliance as the beam is not perfectly built-in [32]. Thus, a correcting factor $\Delta$ is introduced assuming that the real crack is slightly longer $(\alpha+\Delta)$ than the one measured experimentally. $\Delta$ may be found experimentally as the deviation from the origin by plotting the cube root of the compliance as a function of crack length.

$$
G_{l c}=\frac{3 P \delta}{2 B(\alpha+\Delta)}
$$


while the compliance $\mathrm{C}$ is given by,

$$
C^{1 / 3}=\frac{2}{\sqrt[8]{E B}}(\alpha+\Delta)
$$

where $\mathrm{E}$ is the Young's modulus. A constant value for $\Delta$ is assumed during the whole crack propagation procedure.

\subsection{EXPERIMENTAL COMPLianCe Method}

This is the most accurate method, and could be characterized as an alternative method which is to plot compliance versus crack length. It is the most popular theory one in literature [33, 34], where the compliance values are obtained directly from the measured load and displacement values $\left(\mathrm{C}=\delta / \mathrm{P}\right.$ versus $\left.\mathrm{a}^{\mathrm{n}}\right)$. Actually, is a two parameter approach according to,

$$
G_{l c}=\frac{n P \delta}{2 B \alpha}
$$

where $\mathrm{n}$ is the slope of the plot.

\subsection{The AREA Method}

In this method, the crack extension is related directly to the area enclosed between loading and unloading curves. To be more specific, the energy release rate is calculated from the energy consumed by the crack extension divided by the area of the new crack surface $[35,36]$. Thus,

$$
G_{I c}=\frac{\Delta A}{B d \alpha}
$$

where $\Delta \mathrm{A}$ is the area enclosed by the loading-unloading path.

\subsection{Modified Model Proposed By Bishopp ANd DruCKer}

Thin composite specimens, very often used for DCB tests, result in large deflections and rotations due to their low flexural rigidity. The correction to linear beam theory for these factors, introduced by Bishopp and Drucker [37], has recently been developed further by Devitt et al. [38] and applied to a series of glass/epoxy composites of three different thicknesses. Good agreement between predicted and experimental values for the three different thicknesses was observed when a constant average value of EI was used for each laminate.

\subsection{Modified Model Proposed By Freeman}

A finite displacement analysis for the DCB test method was first introduced by Freeman [39]. Williams [40] has developed this model further, to include the effects of end blocks. This formulation is valid for any type of anisotropic elastic behaviour of the beam, since it is based on slender beam analysis and ignores transverse stresses. According to Freeman, the final expression for GIc, ignoring the end block effects, is: 


$$
G_{I c}=\frac{2 P}{B} \sin \varphi_{0}
$$

where $\mathrm{P}$ is the applied load, B the width of the DCB specimen and $\varphi_{0}$, the end slope of the cantilever. The analysis was successfully applied to experimental results.

\subsection{The Proposed Approach}

All the above theories are based on certain assumptions, such as: (1) homogeneity and isotropy; (2) certain geometric conditions are respected; (3) St. Venant's principle applies; and (4) plane sections remain plane after loading. However, these assumptions are hardly ever fullfilled in practice. In that case, it is proposed the following approach [41]. According to the geometry (figure 1),

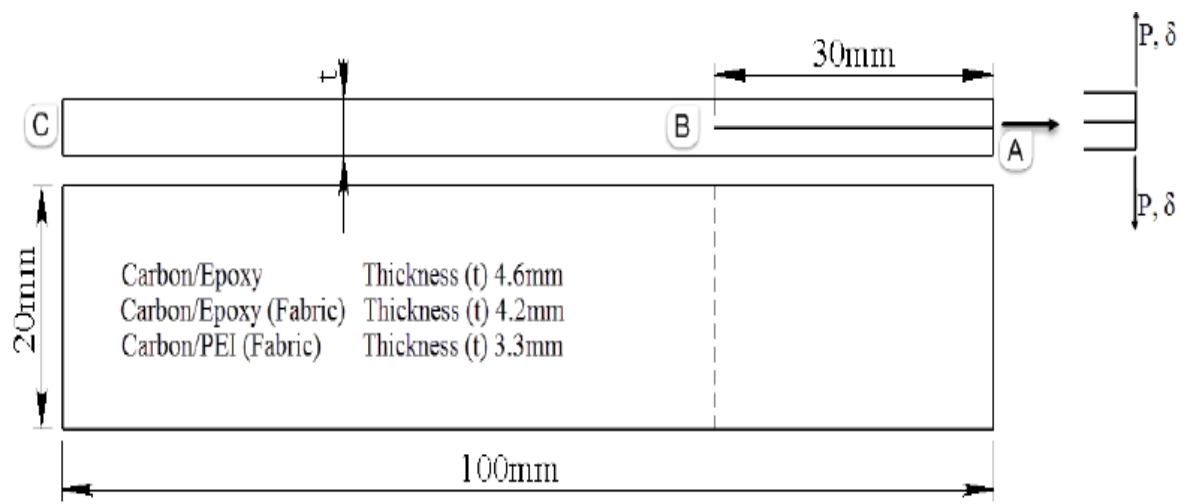

Figure 1. Double Cantilever Beam (Dcb) Geometry.

$$
\delta=\frac{2 P a^{3}}{E B h^{3}}
$$

And

$$
C=\frac{\delta}{P}=\frac{8 a^{3}}{E B h^{3}}(2)
$$

where $\delta$ is the displacement, $\mathrm{P}$ the load, $\alpha$ the crack length, $\mathrm{E}$ the bending modulus, $\mathrm{B}$ the specimen's width, $\mathrm{h}$ the thickness and $\mathrm{C}$ the compliance. From equation (2), we calculate the crack length,

$$
a=\left(\frac{E B C}{8}\right)^{1 / 3}
$$

while from the definition of $\mathrm{G}_{\mathrm{Ic}}$ it follows that: 


$$
G_{I c}=\frac{P^{2}}{2 B} \frac{d C}{d a}=\frac{12 P^{2} a^{2}}{E B^{2} h^{3}}(4)
$$

By introducing expression (3) into (4) we finally find:

$$
G_{I c}=\frac{3 P^{2}}{A}\left(\frac{C^{2}}{E B}\right)^{1 / 3}
$$

where $\mathrm{A}=\mathrm{Bh}$ is the cross-sectional area of the bending beam. Thus, according to equation (5) the parameters for evaluation of $\mathrm{G}_{\mathrm{Ic}}$ are $\mathrm{P}, \mathrm{A}, \mathrm{C}, \mathrm{E}$, and $\mathrm{B}$ which are all completely defined by the experimental procedure applied and the specimen's geometry.

\section{MATerial AND MeThOD}

\subsection{Joint Configuration And MATERial}

The DCB specimen is often used to determine the mode I interlaminar fracture toughness, $\mathrm{G}_{\mathrm{Ic}}$, and it is widely used on unidirectional reinforced laminates. In this finite element study the specimen is composed of two uniform thickness sub laminates with 0 degree composite material plies $(\mathrm{CF} / \mathrm{Ep})$. In figure 1 a schematic overviews of a DCB specimen is shown, while the analyzed materials are shown in table $1[42,43,44]$.

\begin{tabular}{ccc}
\hline \multicolumn{3}{c}{ Unidirectional Carbon/Epoxy Prepreg [22] } \\
\hline $\mathrm{E}_{11}=148 \mathrm{GPa}$ & $\mathrm{E}_{22}=10.5 \mathrm{GPa}$ & $\mathrm{E}_{33}=10.5 \mathrm{GPa}$ \\
$\mathrm{G}_{12}=5.61 \mathrm{GPa}$ & $\mathrm{G}_{13}=5.61 \mathrm{GPa}$ & $\mathrm{G}_{23}=3.17 \mathrm{GPa}$ \\
$\mathrm{v}_{12}=0.27$ & $\mathrm{v}_{13}=0.27$ & $\mathrm{v}_{23}=0.27$ \\
\hline \multicolumn{3}{c}{ Carbon/Epoxy Fabric [23] } \\
\hline $\mathrm{E}_{11}=67 \mathrm{GPa}$ & $\mathrm{E}_{22}=67 \mathrm{GPa}$ & $\mathrm{E}_{33}=5.6 \mathrm{GPa}$ \\
$\mathrm{G}_{12}=5.31 \mathrm{GPa}$ & $\mathrm{G}_{13}=3.07 \mathrm{GPa}$ & $\mathrm{G}_{23}=3.07 \mathrm{GPa}$ \\
$\mathrm{v}_{12}=0.26$ & $\mathrm{v}_{13}=0.35$ & $\mathrm{v}_{23}=0.35$ \\
\hline & Carbon/Polyetherimide Fabric $[24]$ \\
\hline $\mathrm{E}_{11}=57.6 \mathrm{GPa}$ & $\mathrm{E}_{22}=57.6 \mathrm{GPa}$ & $\mathrm{E}_{33}=8.7 \mathrm{GPa}$ \\
$\mathrm{G}_{12}=3.1 \mathrm{GPa}$ & $\mathrm{G}_{13}=2.8 \mathrm{GPa}$ & $\mathrm{G}_{23}=2.8 \mathrm{GPa}$ \\
$\mathrm{v}_{12}=0.3$ & $\mathrm{v}_{13}=0.4$ & $\mathrm{v}_{23}=0.4$ \\
\hline
\end{tabular}

Table 1. Double Cantilever Beam (DCB) geometry.

\subsection{EfFect Of The Fiber Reinforcement And MATrix}

The strengthening ingredient material in a composite is the fiber, which mainly carries the load through the composite laminate. The fiber maintains the rigidity of the composite while impeding crack or damage propagation and can be arranged in many different types of reinforcement. Depending on the type of reinforcement, the fibres can be oriented randomly, all in one direction (unidirectional or UD), or in a number of different directions [45]. Carbon fibres are one of the most advanced and promising engineering materials, and are most commonly used as reinforcements in advanced polymer-matrix composites [46] due to its many unique properties. In 
figure 2, it can be seen the effect of different fiber reinforcements in a brittle epoxy and a tough polyetherimide matrix. The $\mathrm{CF}(\mathrm{UD})$ reinforcements results in comparison to a fabric $\mathrm{CF}$ reinforcement in much lower values for $\mathrm{G}_{\mathrm{Ic}}$, due to inhomogeneity and waviness of the fabric reinforcement which causes a more complex failure and rougher fracture surface profile [47].

Thus the surface per unit crack length becomes larger in fabric reinforced composites. The fiber/matrix bonding can be responsible for different interlaminar fracture toughnesses measured. On the other hand, the tougher the matrix material is, the higher are the values of the interlaminar fracture toughness (figure 3). For the neat polymers, the fracture energy values roughly vary between $\mathrm{G}_{\mathrm{Ic}}=0.1 \mathrm{~kJ} / \mathrm{m}^{2}$ for EP and $2.5 \mathrm{~kJ} / \mathrm{m}^{2}$ for PEI [48]. This means, that the ratio of interlaminar composite toughness to neat resin toughness is high in the case of an EP-matrix, but very low in cases of PEI matrices [47].

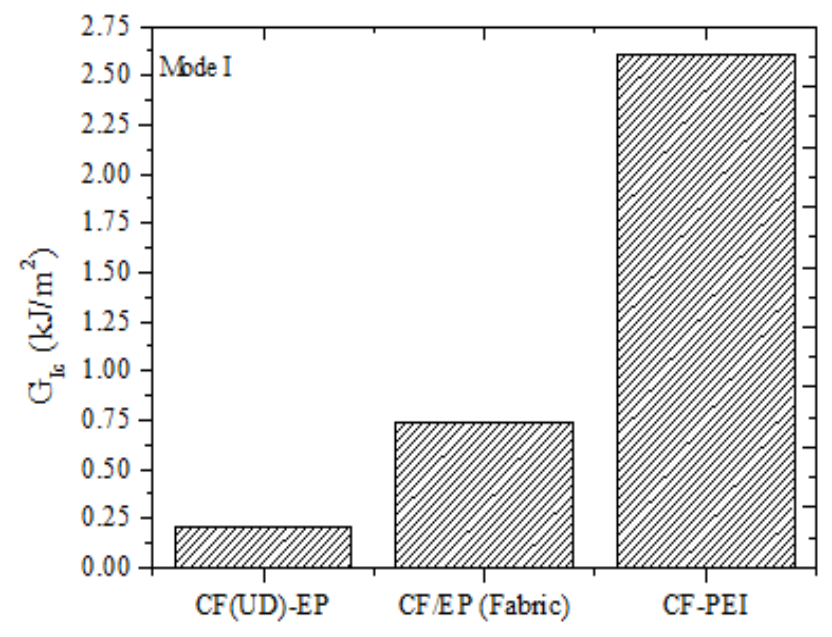

Figure 2. Fiber reinforcement, $\mathrm{G}_{\mathrm{Ic}}$.

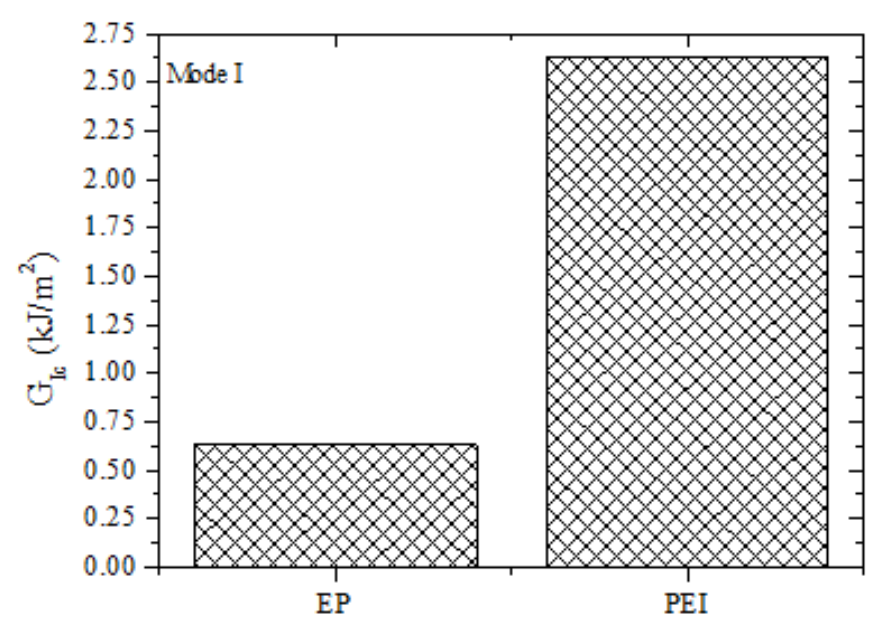

Figure 3. Matrix reinforcement, $\mathrm{G}_{\mathrm{Ic}}$ 


\section{Material And Methods}

Finite element analysis were carried out by using Abaqus. The analysis were based on two dimensional finite element models, by using extended finite element method (XFEM), which simplify the solution of problems such as, (a) the propagation of cracks, the evolution of dislocations, (c) the modeling of grain boundaries and the (d) evolution of phase boundaries. Figure 1 shows the DCB specimen configuration and loading analyzed in this study. The specimen dimensions and materials were selected to represent those typical of currently used test specimens. The CPS4, a 4-node bilinear plane stress quadrilateral was used for two dimensional modeling of the specimen. The size of elements in the specimen was $0.042 \mathrm{~mm}$ using maximum principal stress of $58 \mathrm{MPa}$ (Maxps Damage) and displacement at failure at $5 \mathrm{~mm}$ (Damage evolution). It should be noted that the response after peak load in not as sensitive to mesh refinement. Parametric analysis was performed with a loading displacement $(\delta=3$ and $5 \mathrm{~mm})$ which was applied at the upper and lower corner of the specimen (Figure 1). In order to ensure a smooth propagation, a very small increment values were considered. As, for boundary conditions the left edges of the specimen were restricted as shown in figure 1 (point $\mathrm{C}$ ), while the initial crack (point $\mathrm{AB}=30 \mathrm{~mm})$ as well as the thickness of the resin in all cases was kept constant $(0.0004 \mathrm{~mm})$.

\section{Finite Element And Analytical Results}

\subsection{Finite Element Results}

The stress distributions ahead of the crack tip are analyzed for DCB specimen using carbon/epoxy (CF/EP UD), carbon epoxy fabric (CF/EP) and carbon / polyethermide (CF/PEI). We started by investigating the P- $\delta$ curves, obtained from the numerical model (figure 4 and 5). Once the maximum force is attained, a stable crack propagation accompanied by a decrease in the force, which is in a very good agreement with the experimental results (figure 6a). Moreover, the load decreased at slow rate after a maximum, sometimes with localized stick-slip instabilities [49] occurs. In that case, the critical strain energy release rate could be determined by using parameters such as force, displacement and initial crack length. During the analysis, it was found that the force-displacement curve is dependent on the choice of maximum principal stress. For instance, changing the maximum principal stress (Maxps) values of 50MPa to 10MPa in the case of CF/PEI, the maximum reaction force would be decreased by $11.47 \%$. That means, the crack length for a given displacement will be decreased.

However, for the same loading displacement, the maximum reaction force was found in the case of the CF/Epoxy (UD). The crack was increased by $2.95 \mathrm{~mm}$ and $4.95 \mathrm{~mm}$ for loading displacement 3 and $5 \mathrm{~mm}$, respectively (figure 7). On the other hand, the minimum crack growth was found in the case of CF/PEI (1.07 and 1.70mm). This is true, because PEI increase the viscosity of the resin mixture, which reduces the rate of phase separation [50, 51]. Furthermore, has more resistance towards deformation by an applied force, thus posses high stiffness [52]. Now, if the crack reaches the tougher region, it slows down until the rate of release of elastic stored energy is sufficient to propagate the crack through the tougher region. The release rate of stored energy is then more than that required for stable growth. The crack then accelerates and unstable fracture occurs. Generally, Mode I interlaminar fracture toughness for the satin woven fabric composites greatly depended on both the interfacial properties and weave structure (figure 6b). At last, but not least, for the case of the CF/PEI, the load instantly dropped at several points during the delamination propagation in the load displacement curves, followed by a further increase of the load (figure $6 \mathrm{~b}$, detail squared region). This behaviour was referred to as "stick-slip" crack propagation [53], 
Advances in Materials Science and Engineering: An International Journal (MSEJ), Vol. 4, No. 1/2/3, September2017

accompanying a series of unstable crack propagation and arrest. Again, the finite element results are in good agreement with the experimental results [54].

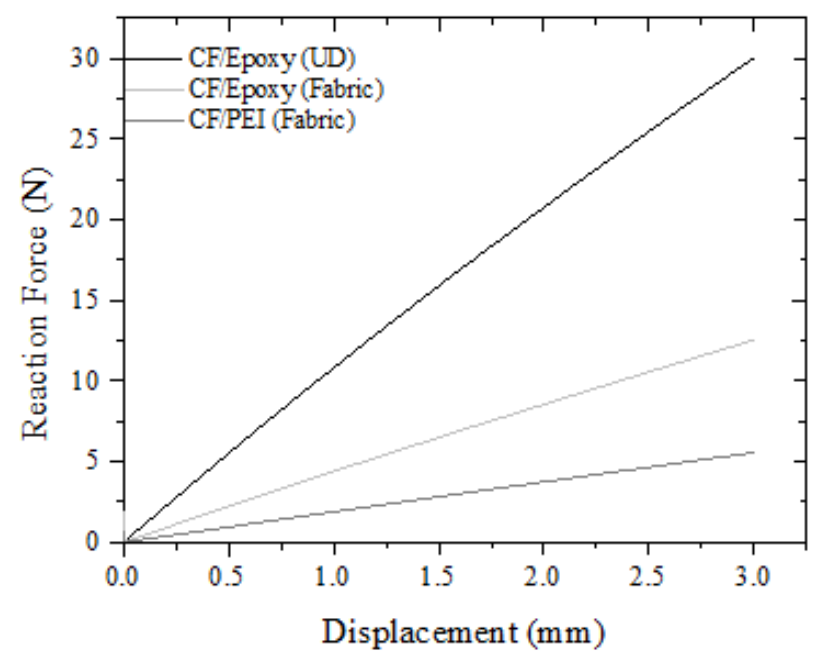

Figure 4. Reaction force displacement relationship $(\delta=3 \mathrm{~mm})$.

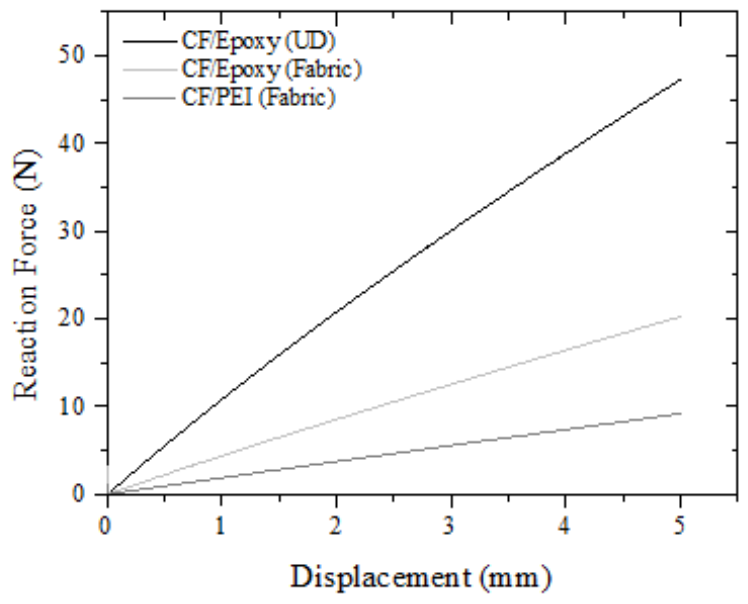

Figure 5. Reaction force displacement relationship $(\delta=5 \mathrm{~mm})$. 
Advances in Materials Science and Engineering: An International Journal (MSEJ), Vol. 4, No. 1/2/3, September2017
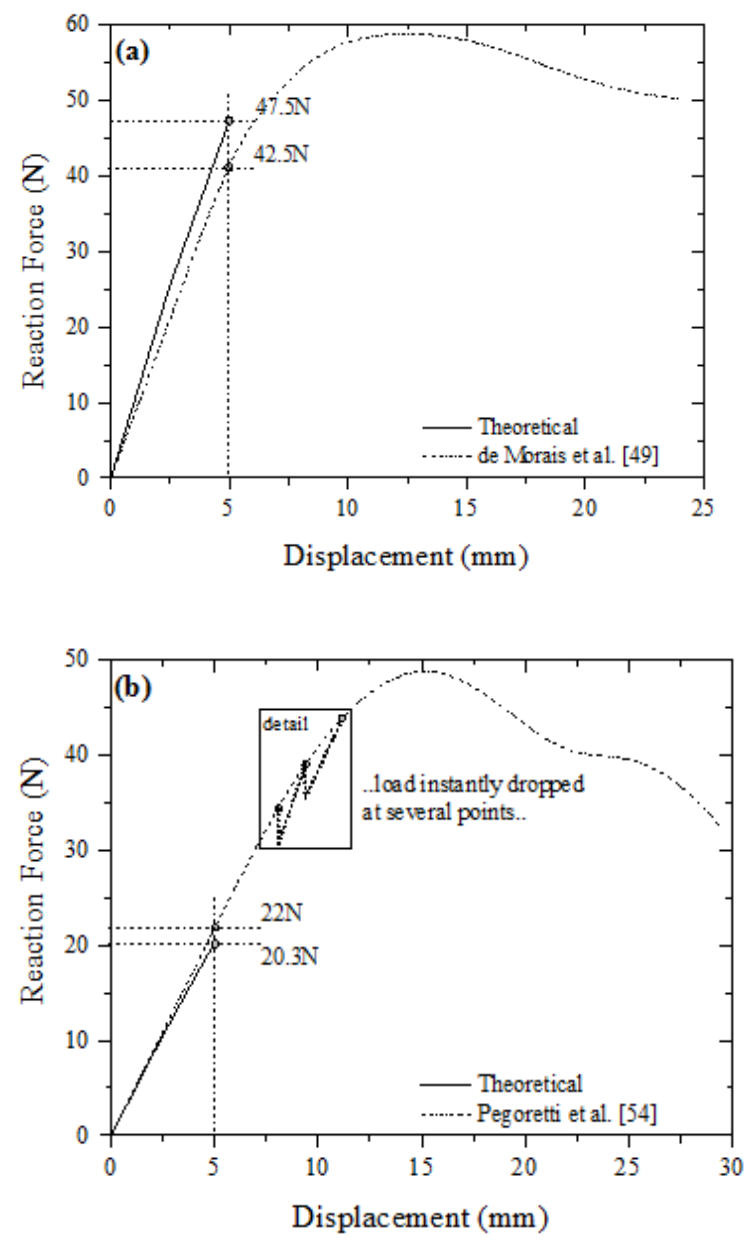

Figure 6. (a) Useful comparisons between FEA vs Experimental results for (a) CF/Epoxy (UD) and (b) CF/Epoxy (Fabric) for $\delta=5 \mathrm{~mm}$.

A closer look at the crack length results indicates that CF/PEI exhibits lower values (for all cases), even when in this material is applied the maximum loading displacement compared to the minimum loading displacement (figure 7).

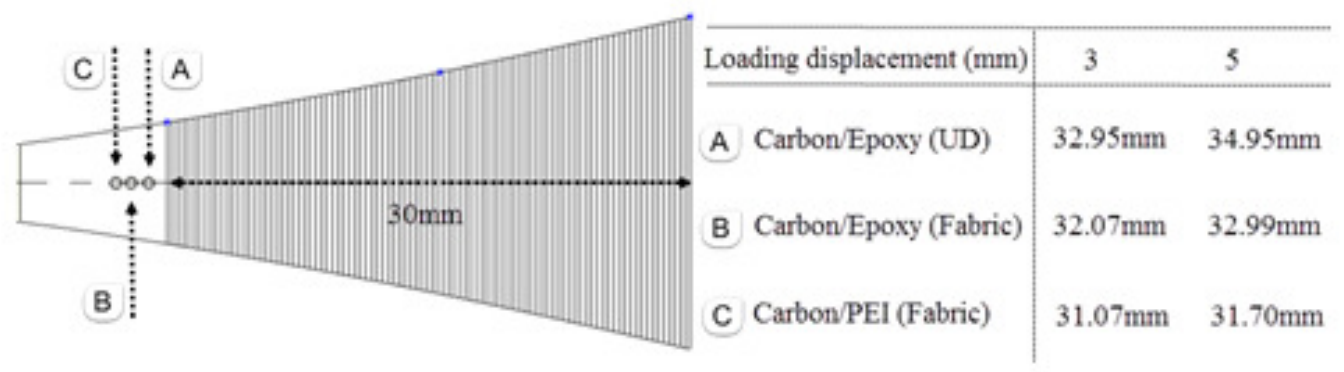

Figure 7. Maximum crack length. 
Further on, figures 8-9 and 10-11 shown the $\sigma_{\mathrm{x}}$ and $\sigma_{\mathrm{y}}$ distributions along the interface, where the maximum values are found at the crack tip. The most dominant stress for the opening mode is $\sigma_{\mathrm{y}}$. It can be seen from figures 8 and 9 , that $\sigma_{\mathrm{y}}$ remains tensile from the crack tip and no compressive. The CF/PEI (UD) curve shows an elevation at the crack tip. It is clear that the differences in the $\sigma_{y}$ distributions related to the differences in the elastic properties as well as in the thickness of the specimens. The higher value of young modulus $\left(\mathrm{E}_{2}\right)$, produced higher stresses. The two fabric materials, have an $\mathrm{E}_{2}$ that is about almost seven and six times more than the CF/EP (UD). In that case, the $\sigma_{y}$ distributions appears to be influenced by the adherends stiffness in the thickness direction and does not seem to be influenced by the adherend stiffness in the longitudinal direction [55]. Furthermore, the ductile matrices to deform plastically is restricted due to the preferential occurance of unstable crack propagation in the woven fabric laminates (figures 12 and 13). As for the critical strain energy release, depends from matrix toughness and the crack initiation region which is usually associated with a slow stable crack growth [56].

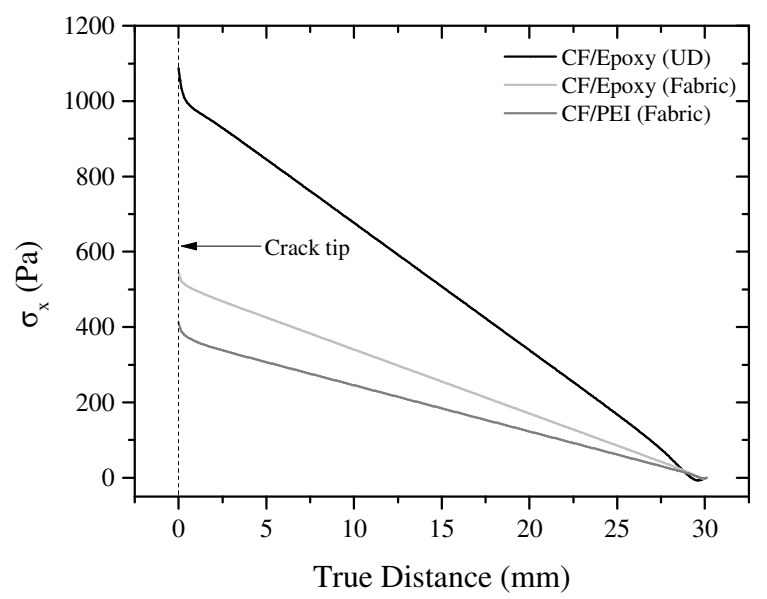

Figure 8. Stress distribution $\left(\sigma_{\mathrm{x}}\right)$ at the interface of substrate and resin $(\delta=3 \mathrm{~mm})$.

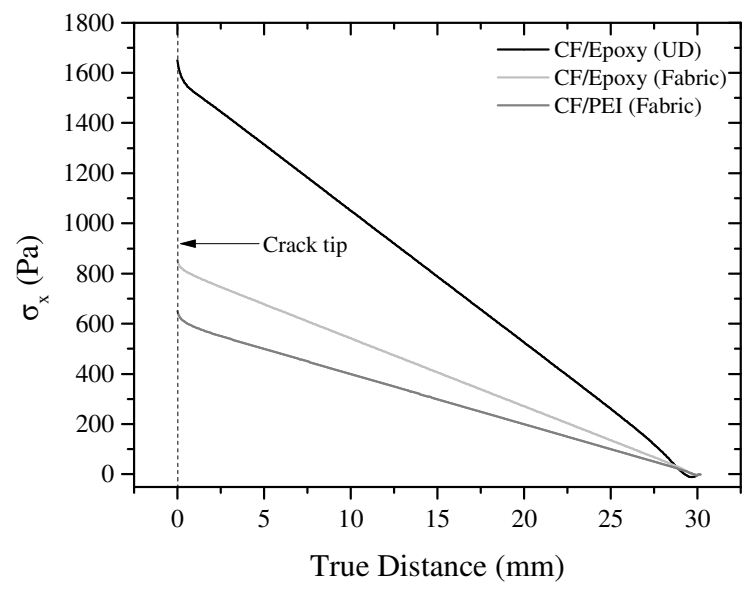

Figure 9. Stress distribution $\left(\sigma_{\mathrm{x}}\right)$ at the interface of substrate and resin $(\delta=5 \mathrm{~mm})$. 
Advances in Materials Science and Engineering: An International Journal (MSEJ), Vol. 4, No. 1/2/3, September2017

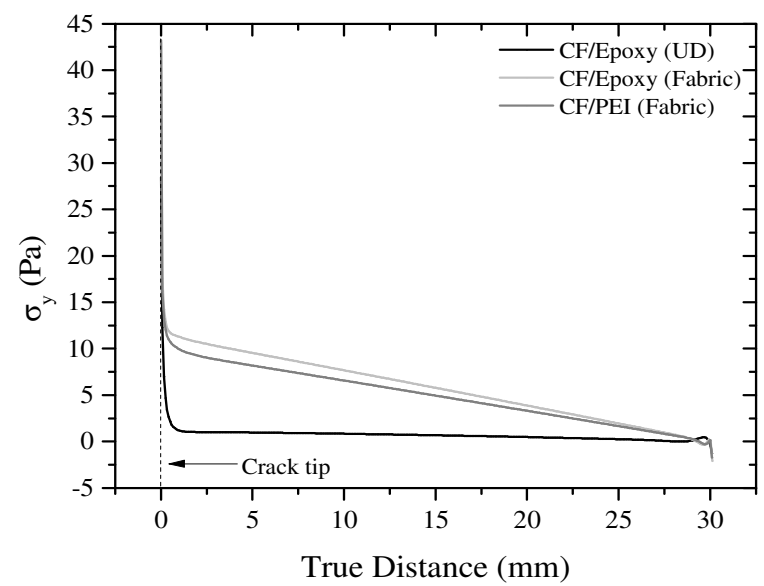

Figure 10. Stress distribution $\left(\sigma_{\mathrm{y}}\right)$ at the interface of substrate and resin $(\delta=3 \mathrm{~mm})$.

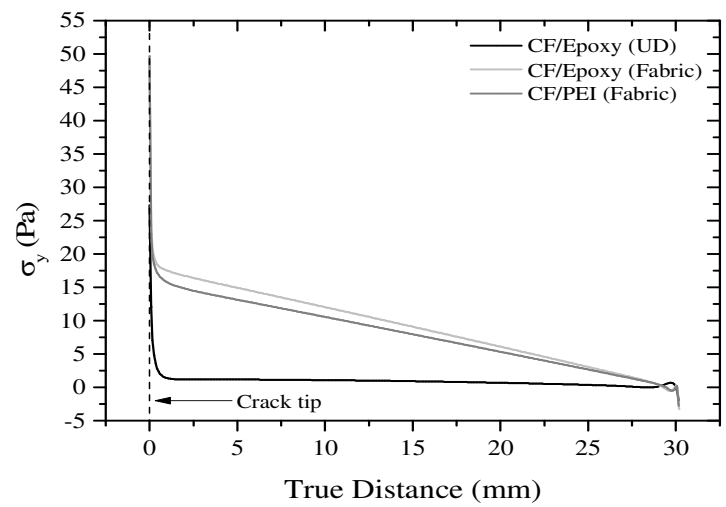

Figure 11. Stress distribution $\left(\sigma_{\mathrm{y}}\right)$ at the interface of substrate and resin $(\delta=5 \mathrm{~mm})$.

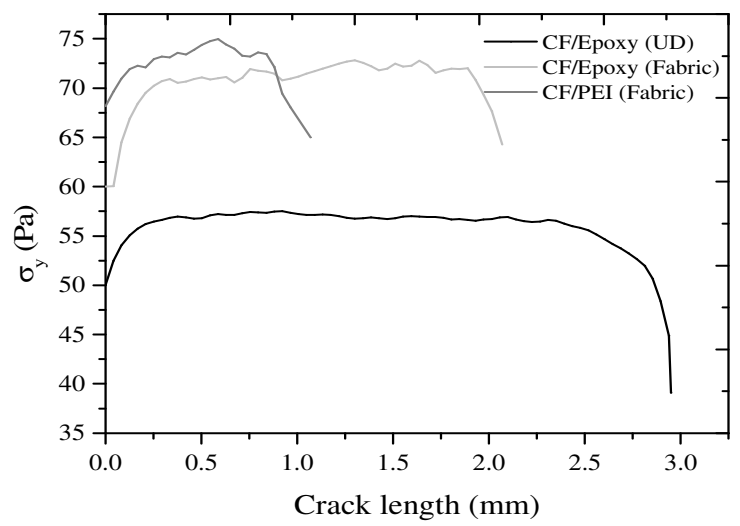

Figure 12. Stress distribution $\left(\sigma_{\mathrm{y}}\right)$ at the interface after the $30 \mathrm{~mm}(\delta=3 \mathrm{~mm})$. 


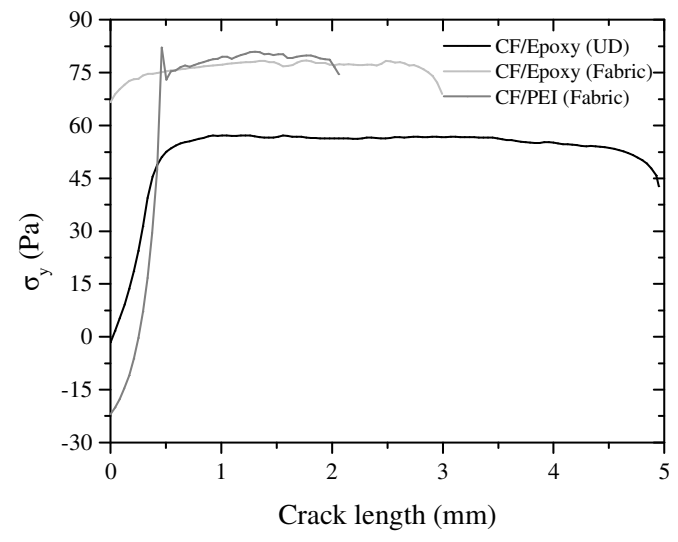

Figure 13. Stress distribution $\left(\sigma_{\mathrm{y}}\right)$ at the interface after the $30 \mathrm{~mm}(\delta=5 \mathrm{~mm})$.

Other parameters such as the specimen width and the effect of adherend transverse thickness appears to had a small effect on the DCB critical strain energy release rate $\mathrm{G}_{\mathrm{Ic}}$.

\subsection{ANALYTICAL RESUltS}

It is well known that in mode I tests, three basic regions appeared in the load-displacement curves, these corresponding to linear elastic, non-linear elastic and non-linear inelastic behaviour. By using the finite element method, it was observed that non-linear elastic behaviour was found after the $30 \mathrm{~mm}$ length (fig. 12 and 13), and this could be as a result of low flexural rigidity, as well as fibre bridging mechanism. During crack propagation some of the fibers were pulled out, these caused the extensive fiber bridging between the crack faces. This feature increased the resistance to delamination, and consequently, a higher load value was required for the crack advance. Therefore, further work is required to clarify these results. it should be mentioned that compliance callibration method is the only data reduction technique, which considers the effect of fiberbridging, but it is sensitive to the accuracy of the displacement measurement.

Another parameter which is important to examine is the crosshead speed. Papanicolaou et al. [41], shows that independently of the displacement rate applied, the linear elastic region is followed by a large non-linear elastic region and this in turn by an inelastic response. The low flexural rigidity of the specimens is mainly due to their low thickness $(2 \mathrm{~h}=3.3-4.6 \mathrm{~mm})$. Thus large displacements and rotations occur, leading to a non-linear elastic response.

Furthermore, results that comes from the above theories (analytical), are summarized in tables 2 and 3. In all cases, the modified model proposed by Freeman gives the highest values, while the end slope of the cantilever $\left(\varphi_{0}\right)$ ranges between $5.20-8.96^{\circ}$. In all cases, crack initiation took place well within the non-linear part (fig. 12 and 13). 
Advances in Materials Science and Engineering: An International Journal (MSEJ), Vol. 4, No. 1/2/3, September2017

\begin{tabular}{|c|c|c|c|c|}
\hline Material & $\mathrm{G}_{\mathrm{Ic, \text {BeamTheory }}}$ & $\mathrm{G}_{\mathrm{Ic} \text {, Corr Bean Th. }}$ & $\mathrm{G}_{\mathrm{Ic} \text {. Freman }}$ & $\mathrm{G}_{\mathrm{Ic} \text {, Proposal Meth. }}$ \\
\hline CF/Ep. (UD) & 225.00 & 205.61 & 272.65 & 194.00 \\
\hline CF/Ep. (Fab.) & 94.25 & 88.17 & 116.92 & 83.10 \\
\hline CF/PEI (Fab.) & 41.86 & 40.23 & 53.59 & 21.80 \\
\hline
\end{tabular}

Table 2. Analytical results $\left(\mathrm{J} / \mathrm{m}^{2}\right)$ for different theories $(\delta=3 \mathrm{~mm})$.

\begin{tabular}{|c|c|c|c|c|}
\hline Material & $\mathrm{G}_{\mathrm{Ic} \text {, Beam Theory }}$ & $\mathrm{G}_{\mathrm{Ic} \text {, Corr. Beam Th. }}$ & $\mathrm{G}_{\mathrm{Ic} \text {, Freeman }}$ & $\mathrm{G}_{\mathrm{Ic} \text {, Proposal Meth. }}$ \\
\hline CF/Ep. (UD) & 591.71 & 338.58 & 670.25 & 480.00 \\
\hline CF/Ep. (Fab.) & 253.59 & 230.37 & 304.06 & 217.00 \\
\hline CF/PEI (Fab.) & 115.2 & 108.83 & 143.53 & 59.40 \\
\hline
\end{tabular}

Table 3. Analytical results $\left(\mathrm{J} / \mathrm{m}^{2}\right)$ for different theories $(\delta=5 \mathrm{~mm})$.

It seems that both beam and corrected beam theory underestimates $G_{\text {Ic }}$ values. Generally, $G_{\text {Ic }}$ increases as $\delta$ increases, but most of the energy supplied to the specimen is therefore consumed in the development of secondary cracks in front of the crack tip, this further splitting resulting in higher $\mathrm{G}_{\mathrm{Ic}}$ values (fig. 14). As already mentioned, in the above theories-methods the fracture toughness values depend on the specific data-reduction method applied. But in our case, the corrected beam theory and the area method is impossible.

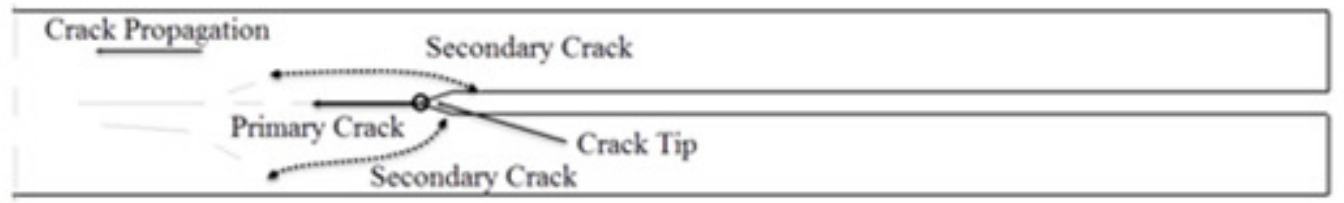

Figure 14: Primary and Secondary Cracks

\section{Conclusions}

A finite element formulation for double cantilever beam is presented and analyzed the distribution of the stresses ahead of the crack tip using the extended finite element code (XFEM) in ABAQUS. XFEM is a partition of unity based method which is able to incorporate functions, typically nonpolynomials into the standard finite element approximating space. The method relies on an enhancement of the approximating space with enrichment functions. Based on the results, it can be concluded that the correct crack path is imperative for determining the true failure strength of the material. The strength will be affected by three parameters such as the length of the initial crack, the mesh refinement and the domain for interaction integral. As it can be seen from the above figures, the maximum stresses are found to increase as the crack grows more than $30 \mathrm{~mm}$. It is also expected, that (a) the tougher the composite laminate is, the greater becomes the effect 
of different kinds of precracks on the crack initiation, and the greater is the difference in crack initiation and propagation values for $\mathrm{G}_{\mathrm{Ic}}$, and (b) fabric reinforced composite laminates result in higher interlaminar fracture toughnesses than unidirectional reinforced materials, because of a more complex fracture behavior. As already mentioned, the load instantly dropped at several points during the delamination propagation in the load displacement curves, followed by a further increase of the load (CF/Ep. and CF/PEI fabrics).

Furthermore, it is important to combine analytical-experimental approach in order to investigate the fiber bridging effect in unidirectional mode I double cantilever beam specimens with midplane delaminations. The bridging law was composed by the product of two terms: the fiber force and the number of bridging fibers per unit area of crack face. The functions of these two parameters were determined based on experiments. The bridging fibers enhance the resistance to delamination and usually the energy release rate increases with the crack length (Resistance-curve effect).

\section{STATEMENT}

This research received no specific grant from any funding agency in the public, commercial, or not for-profit sectors.

\section{REFERENCES}

[1] Garg, AC, (1988) "Delamination - A damage mode in composite structures. Engineering Fracture Mechanics", Vol. 29, pp. 557-584.

[2] Bolotin, VV, (1996) "Delaminations in composite structures: Its origin, buckling, growth and stability", Composites Part B: Engineering. Vol 27B, pp. 129-145.

[3] Tay, TE, (2003) "Characterization and analysis of delamination fracture in composites-An overview of developments from 1990 to 2001", Journal of Applied Mechanics. Vol. 56, pp. 1-32.

[4] O'Brien, TK, (1982), "Characterization of delamination onset and growth in a composite laminate, in damage in composite materials",ASTM STP 775, pp. 140-167.

[5] Ghasemnejad, H., Blackman, BRK., Hadavinia, H et al., (2008), "Experimental studies on fracture characterisation and energy absorption of GFRP composite box structure", Composite Structures. Vol. 88, pp. 253-261.

[6] Blackman, BRK, Hadavinia H, Kinloch AJ, et al., (2003), "The use of cohesive zone model to study the fracture of fiber composite and adhesively-bonded joints", International Journal of Fracture. Vol. 119, pp. 25-46.

[7] Li, S, Thouless, MD, Waas, AM., Schroeder, JA., et al., (2005), "Use of a cohesive-zone model to analyze the fracture of a fiber-reinforced polymer-matrix composite", Engineering Fracture Mechanics. Vol. 65, pp. 537-549.

[8] Broughton, W.R., Koukoulas, T, Woolliams, P., et al., (2013), "Assessment of nanoparticle loading and dispersion in polymeric materials using optical coherence tomography", Polymer Testing. Vol. 32, pp. 1290-1298.

[9] Tehrani, M, Boroujeni, A.Y., Hartman, TB, et al. (2013), "Mechanical characterization and impact damage assessment of a woven carbon fiber reinforced carbon nano-tube-epoxy composite", Composites Science and Technology. Vol. 75, pp. 42-48.

[10] Shams, SS, El-Hajjar, RF, (2013), "Overlay patch repair of scratch damage in carbon fiber/epoxy laminated composites", Composites Part A: Applied Science and Manufacturing. Vol. 49, pp. 148156. 
Advances in Materials Science and Engineering: An International Journal (MSEJ), Vol. 4, No. 1/2/3, September2017

[11] Tserpes, K.I., Labeas, G.N. (2009). Mesomechanical analysis of non-crimp fabric composite structural parts", Composite Structures, vol. 87, p 358-369.

[12] Lecomte-Grosbras, P, Paluch, B, Brieu, M. (2013) , "Characterization of free edge effects: Influence of mechanical properties, microstructure and structure effects", Journal of Composite Materials. Vol. 47, pp. 2823-2834.

[13] Quddos, A, Khan, MB, Khan, RN., et al., (2012) , "Investigation of fiber-reinforced modified epoxy resin composites", Key Engineering Materials. pp. 510-511: 577-584.

[14] Shokrieh, MM, Daneshvar, A, Akbari, S, et al. (2013) , " The use of carbon nanofibers for thermal residual stress reduction in carbon fiber/epoxy laminated composites", Carbon. Vol. 59, pp. 255-263.

[15] Kinloch, AJ, Mohammed, RD, Taylor, AC, et al. (2006), “The interlaminar toughness of carbon-fibre reinforced plastic composites using 'hybrid-toughened' matrices", Journal of Material Science. Vol. 41, pp. 5043-5046.

[16] Bazhenov, SL, (1995), “ Interlaminar and intralaminar fracture modes in 0/90 cross-ply glass/epoxy laminate", Composites. Vol. 26 No.2, pp. 125-133.

[17] ASTM D 6671-01. (2000), "Standard test method for mixed mode I-mode II interlaminar fracture toughness of unidirectional fiber reinforced polymer matrix composites", in annual book of ASTM Stds, pp. 15.03.

[18] ASTM D 5528-94a. (2000), “ Standard test method for mode I interlaminar fracture toughness of unidirectional fiber-reinforced polymer matrix composites", in annual book of ASTM Stds, pp. 15.03 .

[19] Belytschko, T, Black, T, (1999), "Elastic crack growth in finite elements with minimal remeshing", International Journal for Numerical Methods in Engineering. Vol. 45, pp. 602-620.

[20] Moës, N, Dolbow, J, Belytschko, T, (1999), “A finite element method for crack growth without remeshing", International Journal for Numerical Methods in Engineering. Vol. 46, pp. 131-150.

[21] Sukumar, N, Moës, N, Moran, B, et al., (2000), "Extended finite element method for threedimensional crack modeling", Journal for Numerical Methods in Engineering. Vol. 48, pp. 15491570.

[22] Areias, P, Belytschko, T. (2005) , “ Analysis of three-dimensional crack initiation and propagation using the extended finite element method", Journal for Numerical Methods in Engineering. Vol. 63, pp.760-788.

[23] de Borst, R, Gutirrez, M, Wells, G., Remmers, J, et al. (2004), "Cohesive zone models, higher-order continuum theories and reliability methods for computational failure analysis", Journal for Numerical Methods in Engineering. Vol. 60, pp. 289-315.

[24] de Borst, R, Remmers, JJ, Needleman, A, (2006), “ Mesh-independent discrete numerical representations of cohesive-zone models", Engineering Fracture Mechanics. Vol. 73 No. 2, pp. 160177.

[25] Mariani, S, Perego, U, (2003), "Extended finite element method for quasi-brittle fracture", Journal for Numerical Methods in Engineering. Vol. 58, pp.103-126.

[26] Asferg, J, Poulsen, P, Nielsen, L. (2007) , "A consistent partly cracked xfem element for cohesive crack growth", Journal for Numerical Methods in Engineering. Vol. 72, pp. 464-485.

[27] Moës, N, Belytschko, T, (2002), "Extended finite element method for cohesive crack growth", Engineering Fracture Mechanics. Vol. 69 No. 1, pp. 813-833.

[28] El-Sayed, S, Sridharan, S, (2001), "Predicting and tracking interlaminar crack growth in composites using a cohesive layer model", Composites Part B: Engineering. Vol. 32, pp. 545:553. 
[29] Chai, H, (1986), " Bond thickness in adhesive joints and its significance for mode I interlaminar fracture of composites", Composite Material: Design and Testing (Seventh Conference). ASTM STP 893, pp.209- 231.

[30] Crews, JH, Shivakumar, Jr KN, Raju, IS, (1986), "Factors influencing elastic stresses in double cantilever beam specimens", NASA TM-89033, November.

[31] Protocol for Interlaminar fracture Testing No. 1'. European Group on Fracture (EGF), March 1992.

[32] Morais, de AB, Moura, de MF, Marques, AT and Castro, de PT, (2002), "Mode-I interlaminar fracture of carbon/epoxy cross-ply composites", Composites Science and Technology. Vol. 62, pp. 679-686.

[33] Dahlen, C, Springer, GS, (1994), "Delamination growth in composites under cyclic loads", Journal of Composite Materials. Vol. 28, pp. 732-781.

[34] Ozdil, F, Carlsson, LA, Davies, P, (1998), "Beam analysis of angle-ply laminate end notched flexure specimens", Composites Science and Technology. Vol. 58, pp. 1929-1938.

[35] Yang, Z, Sun, CT, (2000), "Interlaminar fracture toughness of a graphite/epoxy multidirectional composite", Journal of Engineering Material and Technology. Vol. 122, pp. 428-433.

[36] Shindo, Y, Horiguchi, K, Wang, R, et al., (2001), "Double cantilever beam measurement and finite element analysis of cryogenic mode I interlaminar fracture toughness of glass-cloth/epoxy laminates", Journal of Engineering Material and Technology. Vol. 123, pp. 191-197.

[37] Bishopp, KE., Drucker, DC, (1945), "Large deflections of cantilever beams", Quartely of Applied Mathematics. Vol. 3, p. 212.

[38] Devitt, DF, Shapery RA, Bradley, WL, (1990), "A method for determining the mode-1 delamination fracture toughness of elastic and viscoelastic composite materials", Journal of Composite Materials. Vol. 14, p. 270

[39] Freeman JC., Phil. Mug. 1946, pp. 37- 855

[40] Williams, JG, (1987), "Large displacement and end block effects in the DCB interlaminar test in modes I and II", Journal of Composite Materials. Vol. 21, pp. 330

[41] Papanicolaou, GC, Bakos, D, (1996), "Interlaminar fracture behaviour of sandwich structures", Journal of Composites Part A: Applied Science and Manufacturing. Vol. 27A, pp. 165-173.

[42] Hemanth, R, Naresh, B, (2014), "Delamination behavior and experimental validation of glass fabric lepoxy matrix and carbon fabric/epoxy composites in mode-I loading", Mechanical Engineering: An International Journal (MEIJ). Vol. 1(1).

[43] Haidar, F, AL-Qrimli., Fadhil, A, Mahdi, Firas, B, Ismail. (2015), "Carbon/epoxy woven composite experimental and numerical simulation to predict tensile performance", Advanced Materials Sciences and Applications. Vol. 4 No.2, pp. 33-41.

[44] Kim, Ki-Young, Ye, Lin, Yan, Cheng. (2005), "Fracture behavior of polyetherimide (PEI) and interlaminar fracture of CF/PEI laminates at elevated temperatures", Polymer Composites. Vol. 26 No. 1,pp. 20-28.

[45] Lassila, LJ, Vallittu, PK, (2004), "The effect of fiber position and polymerization condition on the flexural properties of fiber -reinforced composite", Journal of Contemporary Dental Practice. Vol. $5(2)$.

[46] Mallick, PK, (2007), " Fiber reinforced composites materials, Manufacturing, and Design”, Taylor and Francis Group, 3rd ed., ISBN 10987654321.

[47] Wittich, H, Friedrich, K, Stange, N, (1990), "Interlaminar fracture of fabric reinforced thermoplastic composites. Advanced Composites in Emerging Technologies", Third International Symposium COMP' 90, University of Patras, Greece, August. 
[48] Chang, IY, Lees, JK, (1988), "Recent development in thermoplastic composites: a review of matrix systems and processing methods", Journal of Composite Materials. Vol. 1, pp. 277-296.

[49] de Morais, AB, Pereira, AB, (2007) , "Application of the effective crack method to mode I and mode II interlaminar fracture of carbon/epoxy unidirectional laminates", Composites Part A: Applied Science and Manufacturing. Vol. 38, pp. 785-794.

[50] Cho, JB, Hwang, JW, Cho, K, et al., (1993), "Effects of morphology on toughening of tetrafunctional epoxy resins with poly(etherimide) ", Polymer. Vol. 34 No.23, pp. 4832-4836.

[51] Yamanaka, K, Inoue, T, (1989), "Structure development in epoxy resin modified with poly(ether sulphone) ", Polymer. Vol. 30 No. 4, pp. 662-667.

[52] Kandpal, J, Yadaw, SB, Nagpal, AK, (2013), "Mechanical properties of multifunctional epoxy resin/glass fiber reinforced composites modified with poly(etherimide)", Advanced Materials Letters. Vol. 4 No. 3, pp. 241-249.

[53] Gillespie, JW, Carlsson, Jr LA, Smiley, AJ, (1987), "Rate-Dependent Mode-I Interlaminar in Graphite/Epoxy and Graphite/PEEK", Composites Science and Technology.Vol. 28, pp. 1-15.

[54] Pegoretti, A, Cristelli, I, Migliaresi, C, (2008), "Experimental optimization of the impact energy absorption of epoxy-carbon laminates through controlled delamination", Composites Science and Technology. Vol. 68, pp. 2653-2662.

[55] Crews, HJ, Shivakumar, KN, (1986), "Factors influencing elastic stresses in double cantilever beam specimens", NASA Technical Memorandum (TM) 89033.November.

[56] Lee, LH, Mandell, JF, McGarry, FJ, (1987), "Fracture toughness and crack instability in tough polymers under plane strain conditions", Polymer Engineering and Science. Vol. 27, pp. 1128-1136.

\section{AUTHOR}

Panagiotis Charitidis is researcher at the Center of Orthopaedic Research(C.O.RE) at Center for Interdisciplinary Research and Innovation-Aristotle University of Thessaloniki ( CIRI-AUTH)). He holds Ph.D in applied mechanics from the University of Patras. During this period, he is professor at Democritus University of Xanthi (Greece).

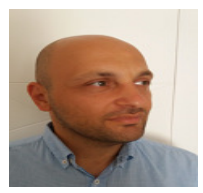

